durch Chlorflüssigkeit aus seiner Verbindung gedrängt werden muss, so ist diese Reaction durch ihre dottergelbe, meistentheils (bei concentrirten Lösungen) trübe Färbung von der dem Amethyst ähnlichen Farbe sehr leicht zu unterscheiden.

\title{
Prüfung der ätherischen Oele auf Verfälschung mit Alkohol;
}

Rebling in Langensalza.

Um eine Verfälschung der Art nachzuweisen, hat Oberdörffer (Vierteljahrsschr. II. 415.) den Platinmohr angewendet, wodurch der im Oele vorhandene Alkohol, wenn er als Dunst damit in Berührung kommt, in Essigsäure verwandelt wird. Obgleich gegen diese interessante Verwendung des Platins nur das einzuwenden, dass die meisten ätherischen Oele sauer sind und ihr Destillat ebenfalls sauer reagirt, weshalb vor der Destillation diese Säure abgestumpft werden muss, so ist diese Art Prüfung jedenfalls umständlicher, und müssen auch einige Unzen in Arbeit genommen werden, wenn die Alkoholbeimischung nur 2-3 Procent betragen sollte.

Ich habe mich stets der Zumischung von Wasser bedient, um eine Alkoholverfälschung der ätherischen Oele nachzuweisen, und da ich hierzu nur 5-10 Tropfen Oel benöthigt war, auch dadurch selbst noch 2 Proc. Verfälschung entdecken kann, so glaube ich mit Recht diese Art Prüfung anempfehlen zu können, als eben so wohlfeil, als schnellfördernd und scharf.

In ein fingerlanges und nur wenig als eine Schreibfeder stärkeres Reagensgläschen tröpfele man 8-10 Tropfen ätherisches Oel, lasse dann 2-3 Tropfen Wasser an der Seitenwand hinablaufen und schwenke einige Male vorsichtig so um, dass zwar beide Flüssigkeiten etwas durcheinander kommen, nicht aber so geschüttelt werden, 
dass eine emulsionähnliche trübe Flïssigkeit entsteht. Enthält das fragliche Oel nur 2-5 Proc. Alkohol, so wird nach einigen Minuten das Oel etwas tribe und weniger durchsichtig, als die gleichzeitig daneben gehaltene, auf gleiche Weise angestellte Probe mit reinem Oele (gleichgültig welches). Ist die Verfälschung mehr als mit 5 Procent Alkohol, dann bedarf es nicht einmal der Gegenprobe mit reinem Oel, und sollte man in Zweifel sein, ,unverfälschte Oele im Vorrath zu haben, um sie zum Gegenversuch anzuwenden: dann bedarf es eben nur eines Reagensglases, um daraus über der Lampe innerhalb einiger Minuten 15-20 Tropfen Ocl iiberzudestilliren, nachdem man das dazu zu verwendende Oel vorher mit einigen Theilen Wasser geschüttelt hat, um den möglichen Alkoholgehalt daraus zu entfernen.

Es bedarf der Erwähnung wohl nicht, dass, um schwache Farbennüancen, Trübungen etc. deutlich wahrnehmen zu können, auf das Halten des Gläschens gegen das Licht viel ankommt. Bei diesem Versuche halte ich das Glas zwar gegen das Licht, aber so, dass ich in der Fntfernung hinter demselben eine dunkle Stelle habe.

\section{Deber Verfälschung der Butter; von \\ Dr. X. Landerer in Athen.}

Es ist bekannt, dass sowohl Butter als Käse eine schlechte Beschaffenheit durch das Futter erlangen können, und dies wird der Fall sein, wenn die auf der Weide befindlichen Thiere gezwungen sind, verschiedene Giftpflanzen zu fressen. In Griechenland will man die Bemerkung gemacht haben, dass die Milch leichter gerinnt, wenn die Thiere (sowohl Ziegen als Kühe) EuphorbiumArten genossen haben; auch soll die Milch schädliche Eigenschaften erlangen, wenn die Thiere die Blätter und Schoten von Anagyris foetida fressen. Durch den Genuss 